\title{
Fluid use in mountain bikers - self-reported practices
}

\author{
S C Rose (MB BCh, MMed Sc (Sports Med)) \\ J A Chipps (M Public Health) \\ E M Peters (MSc (Med), PhD) \\ ${ }^{1}$ Discipline of Physiology, School of Medical Sciences, University of Kwa-Zulu-Natal, Durban \\ ${ }^{2}$ Buyel'empilweni Rehabilitation Research Group, School of Nursing, University of KwaZulu-Natal, Durban
}

\begin{abstract}
Background and objectives. Little is known of the fluid replacement habits of participants in mountain bike (MTB) endurance events. This survey set out to determine the current perceptions and practices of this group of endurance athletes.

Method. Four hundred and twelve participants in the 3day 2006 Sani2C (MTB) race completed questionnaires that elicited information regarding their regular fluid intake practices during competitive MTB endurance events. This included their general approach to fluid replacement, their fluid intake practices (type, amount and frequency), urine output and hydration status.

Results. While $70 \%(N=290)$ reported that they based their fluid intake practices on personal past experiences, less than half the group ( $N=177,43 \%)$ were aware of official sport-specific guidelines. Although $86 \%(N=354)$ reported making use of commercially available sport-specific drinks, consumption of water alone was reported by $34 \%$ of respondents $(N=140)$. The majority $(N=225$, $55 \%)$ of the mountain bikers reported drinking every 16 - 30 minutes during an endurance ride, while 35\% ( $N=$ 144) reported drinking every 0 - 15 minutes. Fifty-three per cent $(N=182)$ of the male respondents and $45 \%(N$ $=23$ ) of female respondents reported a routine intake of $\geq 750 \mathrm{ml}$ per hour during endurance rides. This included 2 women who reported regular intakes of between 1500 and $2000 \mathrm{ml} / \mathrm{hr}$. Only 7 (2\%) reported receiving medical care for dehydration following their participation in previous MTB rides.
\end{abstract}

\section{CORRESPONDENCE:}

\section{E M Peters}

Discipline of Physiology

School of Medical Sciences

University of KwaZulu-Natal

Private Bag 7

Congella 4013

Tel: 031-260 4237

Fax: 031-260 4455

Email: futree@ukzn.ac.za
Conclusions. This survey indicates that although more than half of the mountain bikers did not acknowledge specific awareness of the official fluid replacement guidelines, over $80 \%$ reported drinking regularly during a race, and $52 \%(N=212)$ reported a usual intake of $\geq 750 \mathrm{ml} / \mathrm{hr}$ during endurance races. Until scientific studies have carefully examined the hydration status and fluid replacement needs of mountain bikers, MTB cyclists are cautioned against the practice of over-hydrating.

\section{Introduction}

Over the last few years, off-road cycling or mountain bike (MTB) riding as it is known, has increased in popularity among amateur cyclists, with numerous races being held annually both in South Africa and abroad. These races vary from single-day 'classic' events of $45-75 \mathrm{~km}$ in length to multi-stage, multi-day events ranging between 260 and 900 $\mathrm{km}$ in length. Participants in the races range from full-time professionals who may complete a $45 \mathrm{~km}$ 'classic' in less than 2 hours and a day's stage in 3 - 6 hours, to amateur cyclists who may take up to double that time to cover the same distances. The increased popularity of these endurance and ultra-endurance events has been accompanied by increased interest in fluid replacement and although many studies have been published on runners, cyclists and triathletes completing in endurance events, little is known of the fluid replacement habits of participants in MTB endurance events. We are unaware of any study that has, to date, examined the fluid replacement needs or practices of amateur MTB cyclists who take part in endurance races, whether they be single or multi-day events.

The most recent joint statement released by the American College of Sports Medicine (ACSM), American Dietetic Association and Dieticians of Canada in 2000 regarding fluid use in athletes while training or racing, recommends the intake of 150 - $350 \mathrm{ml}$ of a $4-8 \%$ carbohydrate solution, every 15 - 20 minutes. ${ }^{1}$ This translates into a range varying from $450 \mathrm{ml}$ to $1400 \mathrm{ml} / \mathrm{hr}$. The International Marathon Medical Directors Association (IMMDA) has more recently published an advisory statement on fluid replacement ${ }^{12}$ which recommends that marathon runners, however, drink ad libitum $400-800 \mathrm{ml} / \mathrm{hr}$, with higher rates for the heavier, faster athletes in warm environmental conditions, and the lower rates for the slower runners/walkers completing 
marathon races in cooler environmental conditions. While the IMMDA recommendation is supported by recent evidence of hyponatraemia induced by over-hydration during exercise ${ }^{10,14,17-20}$ what now needs to be established is where, within these ranges, the recommendations for mountain bikers participating in off-road endurance events should lie.

It has been well established that the larger amount of mechanical work done on more robust MTBs and the greater frictional resistance on country roads, results in greater metabolic energy expenditure and heat production when travelling at equivalent speeds in given environmental conditions, than track/ road cycling. ${ }^{3,4,6}$ In addition, MTB cyclists usually carry hydration backpacks which do not promote evaporative cooling, as opposed to road cyclists who only carry drinks bottles on their bikes and runners who do not wear the heavier lycra and nylon attire of the cyclist. As the greater mean wind-chill effect resulting from the increased air movement over body surfaces and higher convective heat losses during cycling may, however, also counter the greater relative heat gain during cycling than running, the fluid replacement needs of MTB cyclists at given cycling speeds in given environmental conditions, require scientific investigation.
Furthermore, multi-day MTB events, such as the Cape Epic or Sani2C are rapidly gaining popularity in South Africa and present an additional challenge to these athletes. Not only does much of the literature encourage cyclists to focus on not losing more than $2 \%$ body mass during each individual stage, ${ }^{17}$ but it has been suggested that the 16 - 20hour rest intervals between 'stages' provide an opportunity to rehydrate fully prior to each of the next stages, in an attempt to maintain fluid status and avoid the cumulative fluid loss and dehydration that may occur over a series of consecutive distance events. ${ }^{5}$

Sound hydration practices of MTB riders participating in endurance events, many of which are multi-day events, are therefore imperative and research needs to be conducted on participants in the sport discipline. The primary purpose of this initial study, the first of its nature on MTB riders, was to survey the regular fluid intake patterns/drinking habits of amateur MTB cyclists. This is followed by a review of the reported regular practices of these MTB riders in relation to the current fluid intake guidelines for other endurance sports including road running and cycling ${ }^{1,9,12,13}$ and a discussion of the variables that will influence fluid replacement needs of these athletes.

\begin{tabular}{|c|c|c|c|c|}
\hline & Men $(N=345)$ & Women $(N=51)$ & $N / S(N=16)$ & Total $(N=412)$ \\
\hline Age (mean \pm SD (years)) & $39.0 \pm 7.6$ & $35.6 \pm 7.2$ & $42.2 \pm 10.1^{*}$ & $38.7 \pm 7.6$ \\
\hline \multicolumn{5}{|c|}{ Hours of riding per week $(N(\%))$} \\
\hline$<5$ & $44(13)$ & $5(10)$ & $4(25)$ & $53(13)$ \\
\hline $6-10$ & $188(55)$ & $27(53)$ & $6(38)$ & $221(54)$ \\
\hline $11-15$ & $95(28)$ & $15(30)$ & $5(31)$ & $115(28)$ \\
\hline $16-20$ & $14(4)$ & $4(8)$ & $1(6)$ & $19(5)$ \\
\hline$>21$ & & 0 & 0 & $4(1)$ \\
\hline \multicolumn{5}{|l|}{ Riding ability $(N(\%))$} \\
\hline 'Week-end warriors' & $44(13)$ & $6(12)$ & $2(13)^{\dagger}$ & $52(13)$ \\
\hline Serious amateurs & $254(74)$ & $35(70)$ & $11(69)^{\dagger}$ & $300(73)$ \\
\hline Elite $\ddagger$ & $40(11)$ & $9(18)$ & $1(7)^{\dagger}$ & $50(12)$ \\
\hline Professional & $1(0)$ & $1(2)$ & $0(0)^{\dagger}$ & $2(1)$ \\
\hline Other & $4(1)$ & 0 & $1(7)^{\dagger}$ & $5(1)$ \\
\hline \multicolumn{5}{|c|}{ Racing experience in last year $(N(\%))^{\S}$} \\
\hline None & $6(2)$ & 0 & 0 & $6(2)$ \\
\hline Fun rider & $18(5)$ & $3(6)$ & $2(13)$ & $23(6)$ \\
\hline$\leq 5$ 'Classics' & $133(39)$ & $32(63)$ & $9(56)$ & $16(4)$ \\
\hline$\leq 6$ 'Classics' & $98(28)$ & $18(35)$ & $2(13)$ & $118(28)$ \\
\hline Previous multistage races & $125(36)$ & $19(37)$ & $4(25)$ & $148(36)$ \\
\hline Other & $22(6)$ & $3(6)$ & $1(6)$ & $26(6)$ \\
\hline \multicolumn{5}{|l|}{${ }^{*} N=6}$. \\
\hline \multicolumn{5}{|c|}{${ }^{\dagger} N=15$} \\
\hline \multicolumn{5}{|c|}{${ }^{\ddagger}$ Regularly attain a top-10 finish in MBT races } \\
\hline$\S$ Several cyclists identified more th & & & & \\
\hline
\end{tabular}




\section{Method}

Permission to conduct this study was obtained from the Bioethics Committee for Research on Human Subjects of the University of KwaZulu-Natal. Anonymity was maintained on all questionnaires. Respondents were categorised according to their gender, age and level of cycling performance, viz. recreational, serious, elite, amateur, or professional.

Information regarding the regular fluid use and drinking habits of amateur MTB riders was obtained using a survey. Questionnaires were handed out to participants in the 2006 three-day Sani2C MTB Race at the race briefing on the evening prior to the start of the race. These elicited information regarding their regular fluid intake practices prior to and during endurance mountain bike rides (i.e. $>2$ hours in duration), including their self-reported general approach towards fluid replacement, their actual fluid intake practices (type, amount and frequency), urine output and hydration status. In order to increase the response rate, a second batch of questionnaires was handed out on the evening of Day 2. No further attempt was made to sample the riders who did not attend the abovementioned race briefings during the course of the multi-day event.

Definitions of dehydration and overhydration were not provided in the questionnaires. This allowed the cyclists to respond using their own diagnostic criteria in an attempt to include all cyclists who felt they had a problem due to inappropriate fluid intake. This also permitted researchers to record the perceptions that currently exist among MBT cyclists regarding fluid use.

\section{Statistics}

Quantitative variables are expressed as mean \pm standard deviation (SD), while categorical data are presented in frequencies and percentages. Binomial / nominal data were compared and tested for association using a chi-square $\left(\chi^{2}\right)$ test. Level of significance was set at $p<0.05$. The database and statistics software used was Epi Info, version 3.32, February 2006 (Centers for Disease Control and Prevention (CDC), Atlanta, USA).

\section{Results}

\section{Sample description}

A total of 412 questionnaires were completed, resulting in a sample comprising $41 \%$ of the total population of athletes registered for the race $(N=996)$. Sixty-nine questionnaires $(17 \%)$ were completed after the second stage of the race. There were no statistically significant differences between the participants who completed the questionnaire before the race and on Day 2 in terms of age and most key variables, except for the recall of amount of fluid taken during races. The results of the two groups are therefore reported together except in terms of hourly volumes of fluid consumed.

A description and categorisation of the respondents is presented in Table I. Overall, 51 (12\%) were female, 345
(84\%) were male and $16(4 \%)$ did not specify their gender. Fifty per cent of respondents were between 30 and 39 years of age, with an average age of $38.6 \pm 7.6$ (range $16-71$ years). Seventy-three per cent $(N=300)$ classified themselves as 'serious amateurs' who participated in more than 5 races a year, while $50(12 \%)$ were elite athletes attaining a regular top 10 finish. One hundred and forty-eight (36\%) of the participants had previously participated in multistage events such as the Cape Epic or Sani2C, with 118 (29\%) of them reporting participating in 6 or more 'classics' (i.e. 45 - 75 km races) in the last year.

\section{Approach to endurance rides}

In reporting their approach to endurance rides and their fluid intake (Table II), the majority $(N=290,70 \%)$ indicated that they use their own personal experience. Advice from friends $(N=111,27 \%)$ and information from magazine articles $(N=$ $87,21 \%)$ were the second and third most common sources of information.

While almost half of the group $(N=177,43 \%)$ were aware of official sports guidelines, only $47(11 \%)$ reported actually using official sport-specific guidelines to assist their approach to fluid intake during endurance rides. When asked to specify a guideline of which they were aware, $48(12 \%)$ mentioned a guideline, with $750 \mathrm{ml} /$ hour $(N=21,5 \%)$ and $500 \mathrm{ml} /$ hour $(N$ $=17,4 \%$ ) being the most common.

Eighty-nine per cent of the riders $(N=368)$ felt that there is a need for more education concerning fluid use and cycling. Specific needs include information on the physiology of hydration, how to evaluate and choose the correct sports drinks, how much to use, how to assess one's hydration status and specific guidelines, especially for novices.

\section{Fluid intake practices during endurance rides}

The most commonly used fluids/drinks consumed during a $>$ 2-hour ride are listed in Table III. Many cyclists gave more than 1 response. Commercially available sports drinks were the most popular drinks during a > 2-hour ride, with 354 respondents (86\%) reporting drinking sports drinks. One hundred and forty respondents (34\%) reported consuming water, and of the $28(7 \%)$ who reported consuming non-sports drinks, Coke and fruit juices were the most popular.

The reason most often reported for selecting a specific drink was that the drink was scientifically designed ( $N=$ $209,51 \%)$. Thirty-four per cent $(N=138)$ liked the taste, and only $28(7 \%)$ reported that they selected the fluid based on advertising. Twenty-seven per cent $(N=113)$ quoted other reasons, with $9 \%(N=36)$ stating that it 'worked' for them based on previous experience, and $7 \%(N=28)$ because they were following advice, primarily from friends and retail bicycle outlets.

\section{Frequency and quantity of intake during a race}

Most of the respondents reported drinking frequently, with $55 \%(N=225)$ reporting drinking every $16-30$ minutes and $35 \%(N=144)$ drinking every $0-15$ minutes. The volumes 


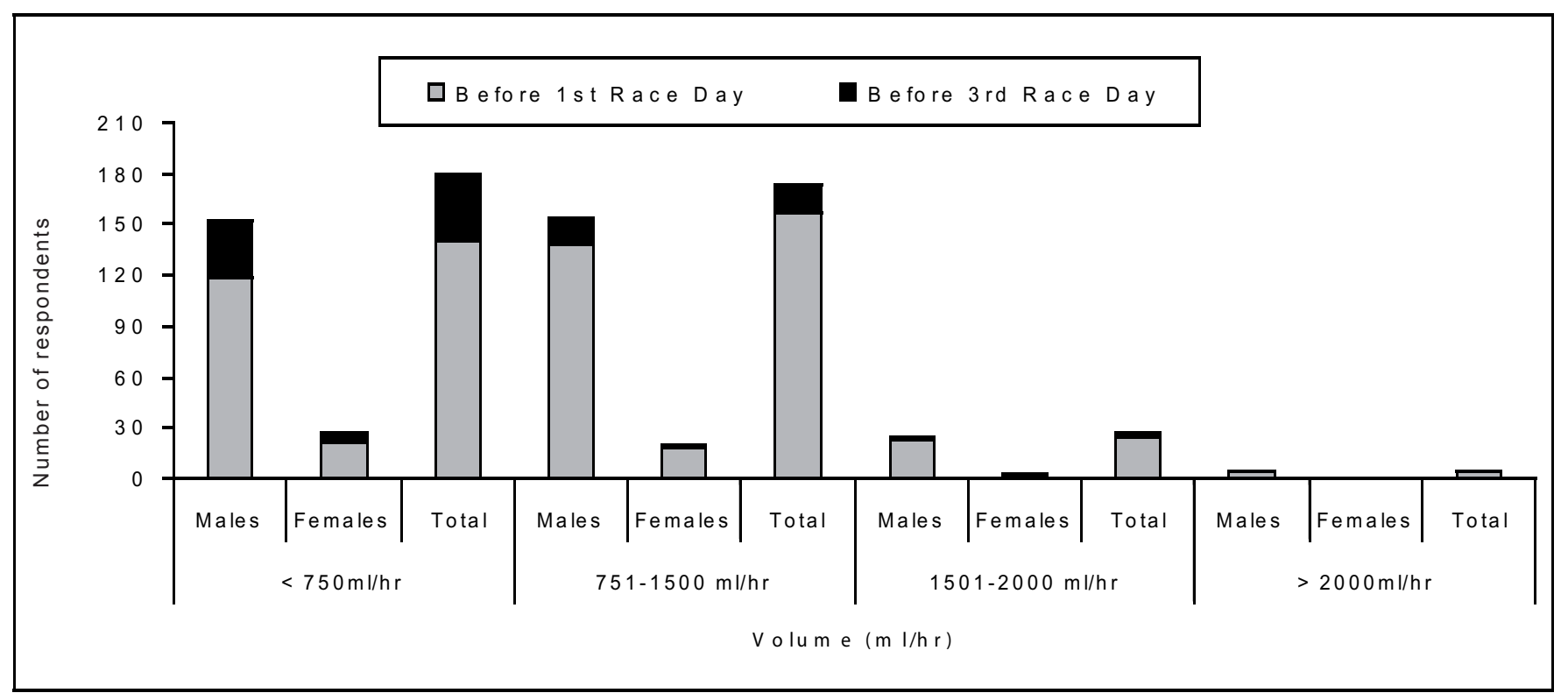

Fig. 1. Quantities of reported fluid consumption per hour by male and female cyclists during endurance MTB races before the first and third stages of the 2006 Sani2C MTB race $\left(N=385^{*}\right)\left(^{*} 12\right.$ did not provide details and 15 did not specify their gender).

\begin{tabular}{|c|c|c|c|c|}
\hline & Men $(N=345)$ & Women $(N=51)$ & $\mathrm{N} / \mathrm{S}(N=16)$ & Total $(N=412)$ \\
\hline \multicolumn{5}{|c|}{ Sources of current approach to fluid use ${ }^{*}$} \\
\hline Advice from friends & $89(26)$ & $14(28)$ & $8(50)$ & $111(27)$ \\
\hline Magazine articles & $77(22)$ & $6(12)$ & $4(25)$ & $87(21)$ \\
\hline Personal experience & $243(70)$ & $39(77)$ & $8(50)$ & $290(70)$ \\
\hline Official sport-specific guidelines & $38(11)$ & $7(14)$ & $2(13)$ & $47(11)$ \\
\hline Other & $18(5)$ & $3(6)$ & 0 & $20(5)$ \\
\hline \multicolumn{5}{|c|}{ Awareness of sport-specific guidelines for fluid use* } \\
\hline Yes & $154(45)$ & $16(31)$ & $7(44)$ & $177(43)$ \\
\hline No & $191(55)$ & $35(69)$ & $9(56)$ & $235(57)$ \\
\hline \multicolumn{5}{|c|}{ *Several cyclists identified more than one factor in their response. } \\
\hline
\end{tabular}

that men and women $(N=385)$ reported consuming per hour (before the first and third stages of the 3-day Sani2C race), are presented graphically in Fig. 1 . While a total of $188(47 \%)$ reported an intake $<750 \mathrm{ml} / \mathrm{hr}, 179(45 \%)$ reported an hourly intake of between 750 and $1500 \mathrm{ml}$, and $33(8 \%)$ an intake of $\geq 1500 \mathrm{ml} / \mathrm{hr}$. A comparison of the volume of fluid intake per hour in the cyclists who completed this section of the questionnaire before the race $(N=337)$ and those who completed it after the first 2 days of the race $(N=63)$, revealed a statistically significant difference between the 2 groups $\left(\chi^{2}\right.$ $=10.61, p=0.031)$, with $65 \%(N=41)$ reporting less than $750 \mathrm{ml}$ per hour after Day 2 as opposed to $44 \%(N=147)$ of the respondents who completed the questionnaire before the start of the 2006 Sani2C MTB race. At no stage did the difference in reported consumption between the men $(N=334)$ and the women $(N=51)$ reach statistical significance $\left(\chi^{2}=\right.$ $2.19, p>0.70)$.
Most respondents did not acknowledge a specific drinking routine before a race $(N=272,66 \%)$. Of the $135(33.0 \%)$ who reported a routine, $49(12 \%)$ reported starting with a sports drink and/or using only sports drink during the event, $41(10 \%)$ reported starting with water, and $12(3 \%)$ starting with a mixture of both.

\section{Urine output}

One hundred and six riders (26\%) stated that they never pass urine during an endurance ride. Forty-three per cent of the respondents $(N=177)$ reported urinating only once every 5 endurance rides, with $62(15 \%)$ urinating once in every 2 rides, and 57 (14\%) urinating every ride. After rides, $122(30 \%)$ acknowledged urinating within half an hour, and $152(37 \%)$ within 30 minutes to an hour. Twenty per cent $(N$ $=82$ ) reported taking between 1 and 2 hours to urinate, and $18(4 \%)$ longer than 2 hours. 


\begin{tabular}{|c|c|c|}
\hline Drinks specified ${ }^{*}$ & $N$ & $\%$ use \\
\hline Water & 140 & 34 \\
\hline Commercially available sports drinks & $354^{*}$ & $86^{*}$ \\
\hline Cytomax & 68 & 17 \\
\hline FIT products (unspecified) & 58 & 14 \\
\hline Energade & 48 & 12 \\
\hline Energy Dynamics & 40 & 10 \\
\hline Powerade & 35 & 9 \\
\hline Octane & 27 & 7 \\
\hline Staminade & 22 & 5 \\
\hline Carbo Supreme & 20 & 5 \\
\hline CarboTrain & 14 & 3 \\
\hline CytoPower & 11 & 3 \\
\hline CarboMax (8), Fastfuel (8), Game (5), Enervit (5), Replenish (5), Enduren (4), Enduromax (3), others (13) & 51 & 12 \\
\hline Non-sports drinks & 28 & 7 \\
\hline Fruit Juices & 7 & 2 \\
\hline Coke & 15 & 4 \\
\hline Other (e.g. soy milk) & 6 & 2 \\
\hline
\end{tabular}

\section{Hydration status}

Fifty-eight per cent of respondents $(N=239)$ felt that when they finish an endurance race of more than 2 hours, they have had enough to drink. Only 90 (22\%) felt they had too little to drink, and $74(18 \%)$ were 'not sure'. Fifty-seven per cent $(N=233)$, however, reported that they felt that they had been dehydrated at least once in every 5 rides, with only 120 (29\%) reporting never considering themselves dehydrated after finishing an endurance ride. Despite the relatively common self-made diagnosis of dehydration, most respondents ( $N=237,58 \%)$ felt that they had no serious problems as a result of not drinking enough, although 112 (27\%) reported performing 'worse', $6(2 \%)$ reported having abandoned previous races and $7(2 \%)$ reported receiving medical care including an intravenous drip, in the past. Other complications reported $(N=45,11 \%)$ included mostly cramps $(N=14,3 \%)$ and headaches $(N=16,4 \%)$. Only $64(16 \%)$ reported a subjective perception of ever drinking too much, but 100 (24\%) acknowledged being 'unsure'. Twenty-seven per cent $(N=$ $51)$ of those who reported consuming less than $750 \mathrm{ml} / \mathrm{hr}$ $(N=188)$, described their performances as worse than expected.

Seventy respondents $(17 \%)$ reported using a specific method to assess their hydrations status. These included the colour of their urine $(N=20)$, thirst $(N=8)$, assessment of weight changes before and after rides $(N=10)$ and performance $(N=4)$.

\section{Discussion}

The first significant finding of this study was that despite the cold weather conditions on the first 2 days of the race which may have encouraged a more conservative estimation of regular fluid intake in the $17 \%$ of the sample $(N=69)$ who filled in the questionnaire after the end of the second day of the race, and inclusion of 51 women in the sample $(12 \%)$, $52 \%(N=212)$ of the mountain bikers reported a regular intake of $>750 \mathrm{ml} / \mathrm{hr}$ (i.e. 1 standard cycle bottle) in endurance races. This is higher than the average hourly fluid intake of $716 \mathrm{ml}$ that has been reported in the New Zealand Ironman, a 1-day multi-sport event that takes competitors between 8 and 17 hours to complete, ${ }^{19}$ but appears to be lower than that reported in cyclists competing in the Tour de France who were found to consume a mean intake of $6.7 \pm 2.0 \mathrm{l} /$ day, while exercising 4 - 5 hours per day. ${ }^{16}$ Although it is difficult to compare the broad categories of intake reported in this study with the $450-1400 \mathrm{ml} / \mathrm{hr}$ range that is recommended in the most recent joint position statement of the ACSM, ADA and DOC, ${ }^{1}$ they do lie close to the upper limit of the recent IMMDA guidelines for marathon runners. ${ }^{12}$ The fact that as many as $33(8 \%)$ of the cyclists reported a regular intake of $\geq$ $1500 \mathrm{ml} / \mathrm{hr}$, may, however, be of concern.

Closer examination of the data reveals that despite these relatively high reported habitual fluid intakes in the majority of this sample of cyclists, $233(57 \%)$ reported that they consider themselves to have been dehydrated at least once in every 5 rides, with 29 (7\%) reporting being dehydrated more often. Although this appears to lend support to the possibility of relatively high fluid intake needs of MTB riders, it is possible 
that the symptoms that the cyclists attributed to dehydration may have been due to a wide range of causes. We need to acknowledge that these are self-reported data which, at this stage, need to be validated using scientific field research and only present preliminary pilot data.

The lack of association between those reporting an intake $<750 \mathrm{ml} / \mathrm{hr}$ and self-reported past history of dehydration ( $N$ $=116, p=0.30$ ), and the equal number reporting previous experiences of dehydration while reporting a regular intake $\geq 750 \mathrm{ml}(N=140)$ also appears to point towards a possible change to a higher habitual intake that may have occurred following previous perceptions of dehydration events. Of the 7 cyclists who acknowledged requiring medical care for 'dehydration' in the past, only 1 reported a current regular intake of $<750 \mathrm{ml} / \mathrm{hr}$ in this survey. Fourteen of the cyclists, however, attributed 'cramps' to dehydration, while others ( $N$ =13) appear to have regarded receiving intravenous fluid post-race and the need to 'abandon the race' as indications of being dehydrated. The theory that cramps and inability to continue exercising are associated with dehydration, has been widely disputed. ${ }^{9}$ Furthermore, there are numerous reports in the literature of inappropriate administration of intravenous fluids following endurance events. ${ }^{10}$ As many of these selfreported perceptions of the cyclists therefore appear not to be in keeping with the present state of knowledge, $9,10,13,21$ this once again supports the need for scientific validation of the status quo and further education of the riders.

While more than half $(52 \%, N=212)$ of the respondents reported a usual intake of $\geq 750 \mathrm{ml} / \mathrm{hr}$ when participating in endurance rides, the effect of additional variables including environmental conditions, body mass, exercise intensity, training status and degree of heat acclimatisation on fluid intake requirements should not be underestimated.

The importance of environmental conditions on attitude to fluid intake is clearly shown when one compares the responses between those who filled in the questionnaire before and after 2 unexpectedly cold days of racing. It is interesting that almost twice as many subjects who reported their regular hourly fluid intakes after the cold (ambient temperature range $9-22^{\circ} \mathrm{C}$ ), wet and windy weather conditions on the first 2 days of the 2006 Sani2C $(N=41)$ recorded intakes of $<750$ $\mathrm{ml} / \mathrm{hr}$, compared with the number of cyclists who recorded intakes of $\geq 750 \mathrm{ml} / \mathrm{hr}(N=22)$.

Body mass is known to be positively correlated with sweat rate and hence fluid intake requirements during exercise. ${ }^{11}$ In contrast to ultradistance runners and competitive road cyclists, it is not uncommon for heavier and older athletes with a more dominant mesomorphic-endomorphic somatotyping to be attracted to MTB racing. This was confirmed by our research group in a subsample of 25 randomly selected male participants in the 2006 Sani2C MTB race who presented with a range of $67-103 \mathrm{~kg}$ and mean of $82.5 \pm 9.3 \mathrm{~kg}$ body mass (SC Rose and EM Peters - unpublished data). These findings may well support the higher fluid intake needs of a considerable proportion of these athletes.
Female ultradistance athletes have been shown to have lower fluid requirements and to be at significantly greater risk of developing hyponatraemia due to fluid overload in ultradistance triathlons than average men. ${ }^{19,20}$ This has been attributed to their lower sweat rates as they are usually smaller, lighter and have smaller fluid compartments, and the longer time taken by women to complete events. ${ }^{16}$ This is supported by the fact that the only reported case of exercise-induced hyponatraemia in a cyclist, has been in a female cyclist taking part in a 1-day cycling event, despite this cyclist having a modest fluid intake throughout the race. ${ }^{2}$ Although the data from this study also confirm a lower reported intake in female cyclists, with $55 \%(N=28)$ reporting an intake of $<750 \mathrm{ml} / \mathrm{hr}$, and the results also confirm a positive association between those women who reported drinking too much/overhydration and those who reported intake of $\geq 750 \mathrm{ml} / \mathrm{hr}\left(\chi^{2}=9.6805\right.$, $p=0.046)$, the fact that 2 women reported regular hourly intakes of 1501 - $2000 \mathrm{ml}$ (Fig. 1), is of concern.

It is also well accepted that racing speed, which determines metabolic rate and sweat rate, is one of the primary determinants of fluid replacement needs. ${ }^{11}$ Interestingly, MTB cyclists who fell into the 'elite' and professional categories in this study (Table I), did not report higher regular fluid intakes than the serious amateurs and recreational cyclists. This would also confirm previous findings ${ }^{14,22}$ and may be in keeping with a previous observation that elite runners have been recorded as having fluid intakes as low as $100 \mathrm{ml} / \mathrm{hr}^{14}$

While heat acclimatisation has been shown to result in enhanced sweat rates ranging between $800 \mathrm{ml} / \mathrm{hr}$ and 900 $\mathrm{ml} / \mathrm{hr}$ and greater water content of the sweat, ${ }^{7}$ endurance training is also well known to increase both blood volume and sweat rate at a given exercise intensity. ${ }^{11}$ We were, however, not able to identify positive association between the volume of fluid taken in by our cyclists and the level of training or performance of these athletes.

Although the findings of this preliminary survey appear to support an average regular intake of $\geq 750 \mathrm{ml} / \mathrm{hr}$ during MTB races, determination of the optimal fluid intake for recreational endurance athletes such as MTB riders, is complex and will vary depending on environmental circumstances, gender, training/performance status and anthropometrical characteristics of the cyclists. As only $43 \%$ of the MTB riders surveyed in this study reported an awareness of official sports guidelines regarding fluid replacement, the education of MTB cyclists regarding the factors that influence their fluid replacement needs, is imperative. The riders need to be made aware of the dynamic nature of endurance events and the need to be able to adapt the guidelines to their particular individual needs and the impact of environmental conditions on these needs.

Providing guidelines for fluid use by MTB cyclists, in particular participants in multistage events is, therefore, no simple matter. Appropriate fluid intake may vary from day to day and a uniform approach may lead to both overand under-hydration depending on the numerous dynamic factors mentioned above. Although there are no case 
reports or clinical trials that unambiguously link exerciseinduced dehydration with life-threatening, exercise-induced disorders, ${ }^{21}$ the ingestion of excessive amounts of water before and during endurance races can cause a reduction in blood sodium concentrations and cerebral oedema, as the osmotic balance across the blood-brain barrier is disrupted. Hyponatraemic encephalopathy, which has been reported in runners, triathletes, army personnel and recreational hikers following fluid overload, can be potentially fatal. ${ }^{8,10}$

The findings of this survey therefore underline the urgent need for scientific field research to be conducted in order to improve the fluid intake practices of this group of endurance athletes. Directions for future research should include assessments of the metabolic and fluid needs of MTB racers in different environmental circumstances, at different intensities of effort by cyclists of different fitness levels, degrees of heat acclimatisation and somatotyping. As the hazards of overhydration and exercise-induced hyponatraemia are well described, ${ }^{9,10,15,20,21}$ it is imperative that the findings of this first preliminary survey which appear to point towards an intake in the upper range of official guidelines, are validated in carefully conducted scientific field studies that examine the fluid status and haematological profile of these athletes under varying conditions.

\section{REFERENCES}

1. American College of Sports Medicine, American Dietetic Association and Dieticians of Canada. Joint Position Statement: Nutrition and Athletic Performance. Med Sci Sports Exerc 2000; 32: 2130-45.

2. Dugas JP, Noakes TD Hyponatraemic encephalopathy despite a modest rate of fluid intake during a $109 \mathrm{~km}$ cycle race. $\mathrm{Br} J$ Sports Med 2005; 39: e38.

3. Impellizzeri FM, Marcora SM, Rampinini E, Mognoni P, Sassi A. Correlations between physiological variables and performance in high level cross country off road cyclists. Br J Sports Med 2005; 39: 747-51.

4. Impellizzeri F, Sassi A, Rodriguez-Alonso M, Mognoni P, Marcora S. Exercise intensity during off-road cycling competitions. Med Sci Sports Exerc 2002; 34:1808-13
5. Kovacs EM, Schmahl RM, Senden JM, Brouns F. Effect of high and low rates of fluid intake on post-exercise rehydration. Int J Sport Nutr Exerc Metab 2002; 12:14-23.

6. Lee H, Martin DT, Anson JM, Grundy D, Hahn AG. Physiological characteristics of successful mountain bikers and professional road cyclists. $J$ Sports Sci 2002; 20: 1001-8.

7. Maughan R, Shirreffs S. Exercise in the heat: challenges and opportunities. J Sports Sci 2004; 22: 917-27.

8. Montain SJ, Cheuvront SN, Sawka MN. Exercise Induced hyponatraemia: quantitative analysis to understand the aetiology. Br J Sports Med 2006; 40: 98-106.

9. Noakes TD. Exercise in the heat. Old ideas, new dogmas. Int Sports Med J 2006: 7: 58-74.

10. Noakes TD, Sharwood K, Speedy D, et al. Three independent biological mechanisms cause exercise-induced hyponatraemia: Evidence from 2 135 weighed competitive athletic performances. Proc Natl Acad Sci USA 2005; 102: 18550-5.

11. Noakes TD, Myburg KH, Du Plessis J, et al. Metabolic rate, not percent dehydration, predict rectal temperature in marathon runners. Med Sci Sports Exerc 1990; 23: 443-9.

12. Noakes TD. IMMDA Advisory Statement on Guidelines for Fluid Replacement during Marathon Running. New Studies in Athletics. IAAF Technical Quarterly 2002; 17: 15-24.

13. Peters EM. Nutritional aspects in ultraendurance exercise. Current Opinion in Nutrition and Metabolic Care 2003; 6: 427-34.

14. Pugh LG, Corbett JL, Johnson RH. Rectal temperatures, weight losses, and sweat rates in marathon running. J Appl Physiol 1967; 23: 347-52.

15. Rehrer N. Fluid and electrolyte balance in ultra-endurance sport. Sports Med 2001; 31:701-15.

16. Saris WH, van Erp-Baart MA, Brouns F, Westerterp KR, ten Hoor F. Study on food intake and energy expenditure during extreme sustained exercise: the Tour de France. Int J Sports Med 1989; 10: S26-S31.

17. Sawka MN. Physiological consequences of hypohydration: exercise performance and thermoregulation. Med Sci Sports Exerc 1992; 24: 657-70.

18. Sharwood K, Collins M, Goedecke J, Wilson G, Noakes TD. Weight changes, sodium levels, and performance in the South African Ironman triathlon. Clin J Sports Med 2002; 12: 391-9.

19. Speedy DB, Noakes TD, Kimber NE, et al. Fluid balance during and after an ironman triathlon. Clin J Sports Med 2001; 11:44-50.

20. Speedy DB, Noakes TD, Rodgers IR, et al. Hyponatraemia in ultradistance triathletes. Med Sci Sports Exerc 1999; 31: 809-15.

21. Speedy DB, Noakes TD, Schneider C. Exercise-associated hyponataemia: a review. Emerg Med 2001; 13:17-27.

22. Wydenham $\mathrm{CH}$, Strydom NB. The danger of inadequate water intake during marathon running. S Afr Med J 1969; 43: 893-6. 